\title{
Minimization of multiproduct fabrication cost featuring rework, commonality, external provider, and postponement
}

\author{
Peng-Cheng Sunga ${ }^{\mathrm{a}}$, Chia-Ming Lai ${ }^{\mathrm{a}}$, Yunsen Wang ${ }^{\mathrm{b}}$ and Yuan-Shyi P. Chiu ${ }^{\mathrm{a}^{*}}$
}

${ }^{a}$ Department of Industrial Engineering and Management, Chaoyang University of Technology, Taiwan

${ }^{b}$ Department. of Accounting and Finance, Feliciano School of Business, Montclair State University, NJ, United States

\section{A B S T R A C T}

\section{Article history:}

Received December 12, 2021

Received in revised format

December 30, 2021

Accepted January 172022

Available online

January 172022

Keywords:

Multiproduct fabrication

Supply chain

Commonality

External provider

Postponement

\begin{abstract}
This study presents a multiproduct fabrication cost-minimization model featuring external providers, commonality, rework, and postponement in the supply chain environment. Customers' requirements simultaneously emphasize quality, variety, and fast response time in current markets. To satisfy customer needs, most manufacturers in various industries (e.g., clothing, household goods, automotive, etc.) plan their multiproduct fabrication by incorporating a postponement strategy, rework process, and an outsourcing option. Motivated by the viewpoints above, this study offers a decision support system to address customers' external expectations while optimizing internal operating expenses and machine utilization. We propose a single-machine, two-stage delayed differentiation system under a rotation cycle policy. All needed common parts are made in stage one, and stage two fabricates different end products. An external provider is hired to supply partially needed common parts to shorten uptime. The defective items are inevitably produced in both stages. They are categorized and reworked to maintain the desired product quality. Finally, we derive an optimal cost-minimization rotation cycle for our model and use a numerical example to investigate the collective and individual influences of reworking, postponement, and outsourcing to external providers on the multiproduct fabrication problem. In summary, this study can offer an optimization solution for production planning in various modern industries.
\end{abstract}

(C) 2022 Growing Science Ltd. All rights reserved.

\section{Introduction}

Customer requirements simultaneously emphasize quality, variety, and fast response in the current markets. To meet the customer's needs, most manufacturers today plan their multi-product fabrication incorporating a postponement strategy, rework process, and an outsourcing option. Motivated by the viewpoints above, this study presents a single-machine twostage delayed differentiation multi-product fabrication system with rework, commonality, and external providers, to address customers' external anticipation and optimize internal operating expenses and machine utilization. Delayed differentiation strategy intends to produce all common parts needed for the multi-product at once. Then, it finishes the distinct end products to reduce the order response time and/or total operating expenses. Iyer et al. (2003) used a postponement model to manage demand uncertainty. Their model incorporated an assumed portion of regular demand to cope with the order in the postponed period. Their policy allowed the postponed demand's capacity to be purchased, and its unit reimbursement was paid back to customers who accepted their needs to be postponed. The authors proposed a power-range distribution to address the potential demand surges in their capacity planning system. They derived the cost-minimized regular capacity for the two-stage demand- postponement capacity planning problem through formulation and analyses. The authors also suggested a few possible extensions to their models. Jewkes and Alfa (2009) used a geometric matrix methodology to decide the optimal semi-finished items' completion percentage and buffer size supplied by external sources in a make-to-order manufacturing system. They used enumerable techniques to find optimal solutions. They concluded the delayed differentiation strategy is in favor when the producer can balance the order delay fulfillment cost with the unsuitable items' expense. İnkaya et al. (2018) explored the influence of cost structure, coordination, and competition on the product pricing and variety decisions * Corresponding author

E-mail address: ypchiu@gm.cyut.edu.tw (Y.-S. P. Chiu)

(C) 2022 Growing Science Ltd. All rights reserved.

doi: $10.5267 /$ j.uscm. 2022.1 .003 
for vertically differentiated industries' supply chains. The authors examined and compared three scenarios of the supply chain's coordination between the manufacturers and assembly firms on the product offers' differentiation issues. Their performance evaluation included: (i) the bill-of-materials cost; (ii) quality levels; (iii) product competition strength; and (iv) partial differentiation option through numerical experiments. Additional studies (Guericke et al., 2012; Chiu et al., 2020a; Duan et al., 2021) examined the impact of postponement strategies on multi-product manufacturing planning and operations control.

Defective items are inevitably produced in most fabrication systems due to diverse unanticipated factors. These items must be reworked (if repairable) or removed to achieve the desired product quality. Abboud (1996) proposed an algorithm to explore a two-echelon Markovian fabrication system comprising repairable goods. The time to a machine failure and the needed time for repairing products are assumed following an exponential distribution. The researchers presented an algorithm to jointly decide the optimal number of repair channels and machines to meet the desired service level and minimize system expenses. Li (2004) analyzed the throughput performance of a fabrication system featuring rework loops. The author used the overlapping decomposition approach by decomposing the system into serial overlapping fabrication lines to study the interactions of modified machines and buffers in the design and estimate their relative throughput performance. In addition, an automotive assembly line case demonstrated the proposed framework. Krishnamoorthi and Panayappan (2013) studied an imperfect economic production quantity system with a rework process for defects. Two separate models were studied, one allows shortages, and the other disallows shortages. The authors developed mathematical models to decide each model's cost-minimized fabrication lot size and verified them numerically. Al-Salamah (2019) explored the imperfect EPQ model featuring the rework process with variable repairing rates synchronously or asynchronously. In their synchronous case, the defective goods are reworked right away as they are produced. While, in the asynchronous example, the rework of faulty items waits until the fabrication batch completes. The author built two separate models to represent the problems and derived the cost-minimization batch sizes and backorders under various rework rates. Other recent works studied the impact of various defect matters and rework strategies on fabrication-inventory planning and control (Al Taweel, 2019; Homolka et al., 2019; Siouris et al., 2019; Abukhader and Onbaşığlu, 2021; Chiu et al., 2021; Daryanto and Christata, 2021; Suroso et al., 2021; Tóth and Kulcsár, 2021; Yamada et al., 2021).

Most manufacturers always seek an effective strategy to reduce their production uptimes and shorten their orders' response times. To subcontract a portion of their production to external suppliers is often chosen. Arnold (2000) built an outsourcing model comprising institutional economic theory alternatives to analyze and explore the impact of outsourcing and relating decision-making. The author employed the analytical approach incorporating core competencies and transaction cost economics to recommend outsourcing decisions and managerial implications. Araz et al. (2007) used fuzzy goal programming (FGP) to build a system to evaluate and manage a textile firm's outsourcer. The authors first decided on the firm's objectives and the method and criteria of the outsourcer evaluation system. The most suitable strategic outsourcer partners were chosen, along with quantities allocated to these external suppliers. Lastly, the results generated from their proposed method are compared to the firm's current outsourcer status to verify their proposed system's performance. Kaipia and Turkulainen (2016) explored the impact of quality and cost priorities on outsourcing relationships between contract suppliers and buyers. The authors used eight real cases from the electronics and food industries to investigate different integration modes before and at the early production stage for the outsourcing relationship. The results indicated considerable resources are required after an outsourcing decision was made, and integrating and managing outsourcing relationships lead to a successful supplier-buyer relationship. Other recent works (Sadjadi et al., 2018; Skowronski and Benton, 2018; Danasabe et al., 2019; Chiu et al., 2020b) examined the impact of diverse outsourcing alternatives on manufacturing planning and corporation operation management. As few past studies investigated the individual/combined effect of rework, postponement, and outsourcings on the multi-product fabrication problem, this work intends to fill this gap.

\section{Materials and Methods}

This study proposes a postponement model for multiproduct fabrication decisions incorporating commonality, rework, and external sources. The notation is defined in Appendix A.

\subsection{Description and assumption}

A postponement model for multiproduct fabrication decisions incorporating commonality, rework, and the external source is investigated. The problem is specifically described below: (i) it is a two-stage multiproduct fabrication problem; (ii) it features the commonality of intermediate parts and its outsourcing option, the delayed differentiation, and the reworking of faulty items; (iii) all mutual/common parts are made in stage 1 , and $L$ end products (where $i=1,2, \ldots, L$ ) are produced in stage 2 (see Figure 1); (iv) we assume constant annual demand $\lambda_{i}$ for end product $i$; (v) a constant mutual part's completion rate $\gamma$ is assumed and fabricating rate $P_{1,0}$ depends on $\gamma$; (vi) the finished goods' fabrication rate $P_{1, i}$ is dependent on $\gamma$ as well. For instance, if $\gamma$ is 0.50 , then both fabricating rates $P_{1,0}$ and $P_{1, i}$ become two times their standard production rate as in a singlestage process; (vii) a $\pi_{0}$ portion of the mutual parts is provided by an outsourcer to reduce its uptime. Thus, a different unit $\operatorname{cost} C_{\pi 0}$ and setup cost $K_{\pi 0}$ are connected with this outsourcing policy (refer to Eqs. (1) and (2)). (h) the random nonconforming ratios $x_{0}$ and $x_{i}$ are experienced in both stages. Their defects can be repaired at the rates of $P_{2,0}$ and $P_{2, i}$ per year (see Fig. 1 and Fig. 3); (i) a preset receipt schedule for outsourcing common parts is after the rework times (See Fig. 1). 


$$
\begin{aligned}
& C_{\pi 0}=\left(1+\beta_{2,0}\right) C_{0} \\
& K_{\pi 0}=\left(1+\beta_{1,0}\right) K_{0}
\end{aligned}
$$

where $C_{0}, K_{0}, \beta_{2,0}$, and $\beta_{1,0}$ stand for the in-house unit, setup costs, and connecting factors. For example, $\beta_{1,0}=-0.65$ indicates $K_{\pi 0}$ is $65 \%$ less than $K_{0}$, and $\beta_{2,0}=0.22$ indicates $C_{\pi 0}$ is $18 \%$ more than $C_{0}$, etc. Fig. 1 depicts the stock level of our multiproduct manufacturing decision model with rework, commonality, the external source, and postponement. It describes that common parts' stock level rises to $H_{1,0}$ when stage one's uptime completes. It goes on growing to $H_{2,0}$ when its rework ends. Upon receiving the outsourced common parts from the external source, the common parts reach the highest point $H_{3,0}$. Fig. 1 also points out that the level of common parts starts to decline as the fabrication of $L$ distinct end products begins. The progress of separate common parts' levels for each finished goods' production is shown in Fig. 2. Further, Fig. 1 specifies each finished goods' inventory level rises up to $H_{1, i}$ when their uptime completes; and it further goes up to $H_{2, i}$ when their rework finish. Stock-out conditions are not allowed. So $\left(P_{1, i}-d_{1, i}-\lambda_{i}\right)$ and $\left(P_{1,0}-d_{1,0}\right)$ must be $>0$. The level of faulty finished goods and mutual parts are shown in Fig. 3. It can be seen, the nonconforming mutual parts' level rises maximally to $\left(d_{1,0} t_{1,0}\right)$ when uptime completes, and it declines to zero when the rework finishes. The nonconforming finished stock level reaches maximally $\left(d_{1, i} t_{1, i}\right)$ before the rework begins in stage 2 .

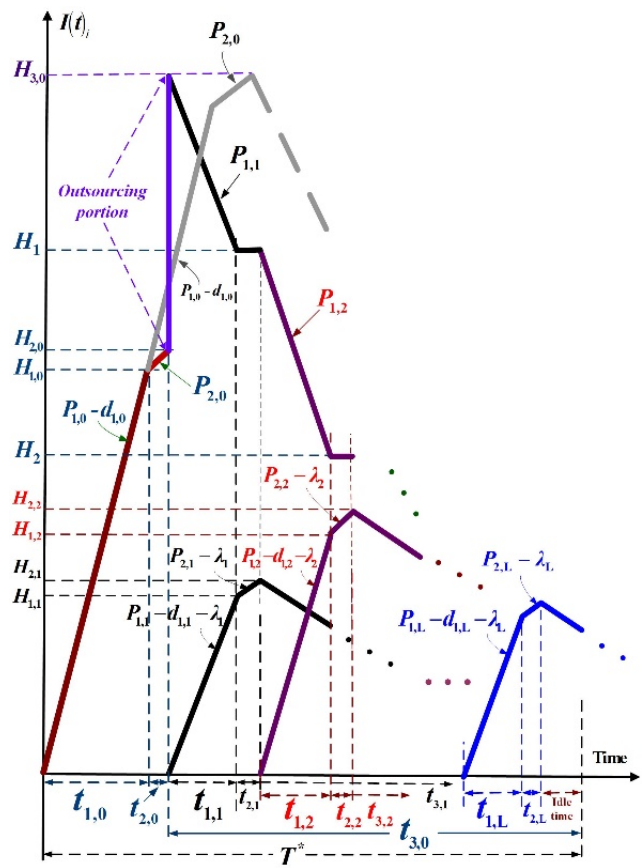

Fig. 1. The stock status of the proposed multiproduct fabrication problem considering rework, commonality, external source, and postponement compared with the same problem without outsourcing policy (in grey)

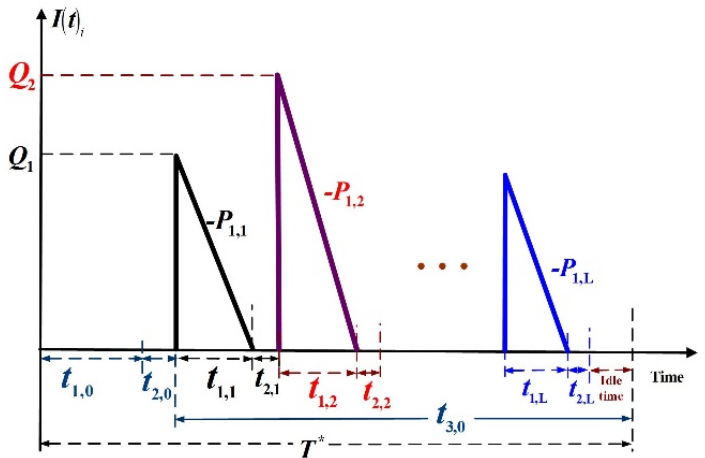

Fig. 2. The progress of separate common parts' levels for each end product's production

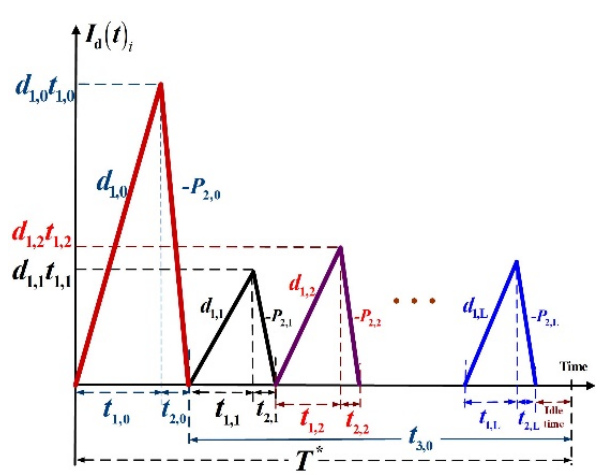

Fig. 3. The levels of faulty end products and common parts 


\subsection{Stage two's formulation}

For $i=1,2, \ldots, L$, the following equations are observed from stage 2 of our study (see Fig. 1 to Fig. 3):

$$
\begin{aligned}
& Q_{i}=\lambda_{i} T \\
& T=t_{1, i}+t_{2, i}+t_{3, i}=\frac{Q_{i}}{\lambda_{i}} \\
& t_{1, i}=\frac{H_{1, i}}{P_{1, i}-d_{1, i}-\lambda_{i}}=\frac{Q_{i}}{P_{1, i}} \\
& t_{2, i}=\frac{x_{i} Q_{i}}{P_{2, i}} \\
& H_{1, i}=t_{1, i}\left(P_{1, i}-d_{1, i}-\lambda_{i}\right) \\
& t_{3, i}=\frac{H_{2, i}}{\lambda_{i}} \\
& H_{2, i}=\left(P_{2, i}-\lambda_{i}\right) t_{2, i}+H_{1, i}
\end{aligned}
$$

From Eq. (9), one knows the common parts' requirements are as follows:

$$
H_{3,0}=\sum_{i=1}^{L} Q_{i}=\sum_{i=1}^{L} \lambda_{i} T
$$

\subsection{Model formulation in stage one}

The following equations are observed from stage one of our study (see Fig. 1 to Fig. 3):

$$
\begin{aligned}
& \sum_{0}=\frac{\sum_{i=1}^{L} Q_{i}}{T} \\
& H_{3,0}-H_{2,0}=\sum_{i=1}^{L} Q_{i}-H_{2,0}=\pi_{0}\left(\sum_{i=1}^{L} Q_{i}\right) \\
& H_{2,0}=\left(\sum_{i=1}^{L} Q_{i}\right)\left(1-\pi_{0}\right) \\
& Q_{0}=H_{2,0} \\
& t_{1,0}=\frac{H_{1,0}}{P_{1,0}-d_{1,0}}=\frac{Q_{0}}{P_{1,0}} \\
& t_{2,0}=\frac{x_{0} Q_{0}}{P_{2,0}}=\frac{H_{2,0}-H_{1,0}}{P_{2,0}} \\
& H_{2,0}=H_{1,0}+P_{2,0} t_{2,0} \\
& H_{1}=H_{3,0}-Q_{1} \\
& H_{1,0}=t_{1,0}\left(P_{1,0}-d_{1,0}\right) \\
& T=t_{1,0}+t_{2,0}+t_{3,0} \\
& H_{i}=H_{(i-1)}-Q_{i}, \text { for } i=2,3, \ldots, L \\
& H_{L}=H_{(L-1)}-Q_{L}=0
\end{aligned}
$$

\section{Results and discussions}

\subsection{System cost analysis}

The total cost in a replenishing cycle $T C(T)$ includes the following: the cost incurred in (A) the first stage's outsourcing, variable and setup (in-house) costs, and the internal rework and holding costs; (B) stage two: the sum of the manufacturing variable, setup, and holding costs for $L$ distinct end products. So, $T C(T)$ is as follows: 


$$
\begin{aligned}
& T C(T)=\pi_{0}\left(\sum_{i=1}^{L} Q_{i}\right) C_{\pi 0}+K_{\pi 0}+Q_{0} C_{0}+K_{0}+\left(x_{0} Q_{0}\right) C_{R, 0}+h_{2,0}\left(\frac{d_{1,0} t_{1,0}}{2}\right)\left(t_{2,0}\right) \\
& +h_{1,0}\left[\frac{H_{1,0} t_{1,0}}{2}+\frac{d_{1,0} t_{1,0}}{2}\left(t_{1,0}\right)+\frac{H_{2,0}+H_{1,0}}{2}\left(t_{2,0}\right)+\sum_{i=1}^{L}\left[H_{i}\left(t_{1, i}+t_{2, i}\right)+\frac{Q_{i}}{2}\left(t_{1, i}\right)\right]\right] \\
& +\sum_{i=1}^{L}\left\{K_{i}+Q_{i} C_{i}+\left(x_{i} Q_{i}\right) C_{R, i}+h_{2, i}\left(t_{2, i}\right)\left(\frac{d_{1, i} t_{1, i}}{2}\right)+h_{1, i}\left[\frac{H_{1, i} t_{1, i}}{2}+\frac{d_{1, i} t_{1, i}}{2}\left(t_{1, i}\right)+\frac{H_{2, i}}{2}\left(t_{3, i}\right)+\frac{H_{2, i}+H_{1, i}}{2}\left(t_{2, i}\right)\right]\right\}
\end{aligned}
$$

$E[T C U(T)]$ can be derived using the following steps: (a) using $E\left[x_{0}\right]$ and $E\left[x_{i}\right]$ to cope with the faulty mutual parts and finished goods' randomness; and (b) substitute Eqs. (3) to (22) in Eq. (23) and calculating $E[T C(T)] / E[T]$. With additional derivation, $E[T C U(T)]$ becomes as follows:

$$
\left\{\begin{aligned}
C_{\pi 0}\left(\pi_{0} \lambda_{0}\right)+ & \frac{K_{\pi 0}}{T}+\frac{K_{0}}{T}+C_{0}\left(1-\pi_{0}\right) \lambda_{0}+E\left[x_{0}\right]\left(1-\pi_{0}\right) \lambda_{0} C_{R, 0}+\frac{E\left[x_{0}\right]^{2}}{P_{2,0}} \frac{h_{2,0} \lambda_{0}{ }^{2} T\left(1-\pi_{0}\right)^{2}}{2} \\
+\sum_{i=1}^{L}\left(\frac{\lambda_{i}^{2} T}{2 P_{1, i}}\right) h_{1,0}+\frac{h_{1,0} T \lambda_{0}^{2}\left(1-\pi_{0}\right)^{2} E_{0 P}}{2}+h_{1,0} \sum_{i=1}^{L}\left[\left(\sum_{i=1}^{L} \lambda_{i}-\sum_{j=1}^{i} \lambda_{j}\right)\left(\frac{\lambda_{i} T}{P_{1, i}}+\frac{\lambda_{i} T E\left[x_{i}\right]}{P_{2, i}}\right)\right] & \\
& +\sum_{i=1}^{L}\left\{\lambda_{i} C_{i}+\frac{K_{i}}{T}+\lambda_{i} E\left[x_{i}\right] C_{R, i}+\frac{E\left[x_{i}\right]^{2}}{P_{2, i}} \frac{h_{2, i} T \lambda_{i}^{2}}{2}+\frac{h_{1, i} T \lambda_{i}^{2}}{2}\left[\frac{1}{\lambda_{i}}-\frac{E\left[x_{i}\right]^{2}}{P_{2, i}}-\frac{1}{P_{1, i}}\right]\right\}
\end{aligned}\right.
$$

where $E_{0 P}$ denotes the following:

$$
E_{0 P}=\left[\frac{1}{P_{1,0}}+\frac{\left(1-E\left[x_{0}\right]\right) E\left[x_{0}\right]}{P_{2,0}}+\frac{E\left[x_{0}\right]}{P_{2,0}}\right]
$$

\subsection{Solving $T^{*}$}

The $1^{\text {st }}$ and $2^{\text {nd }}$ derivatives of $E[T C U(T)]$ are applied as follows:

$$
\begin{aligned}
& \begin{aligned}
\frac{d E[T C U(T)]}{d T}=\left\{\begin{array}{l}
-\frac{K_{\pi 0}}{T^{2}}-\frac{K_{0}}{T^{2}}+\frac{E\left[x_{0}\right]^{2}}{P_{2,0}} \frac{h_{2,0} \lambda_{0}^{2}\left(1-\pi_{0}\right)^{2}}{2}+h_{1,0} \sum_{i=1}^{L}\left(\frac{\lambda_{i}^{2}}{2 P_{1, i}}\right) \\
+\frac{h_{1,0} \lambda_{0}^{2}\left(1-\pi_{0}\right)^{2} E_{0 P}}{2}+h_{1,0} \sum_{i=1}^{L}\left[\left(\frac{\lambda_{i}}{P_{1, i}}+\frac{\lambda_{i} E\left[x_{i}\right]}{P_{2, i}}\right)\left(\sum_{i=1}^{L} \lambda_{i}-\sum_{j=1}^{i} \lambda_{j}\right)\right]
\end{array}\right\} \\
+\sum_{i=1}^{L}\left\{-\frac{K_{i}}{T^{2}}+\frac{E\left[x_{i}\right]^{2}}{P_{2, i}} \frac{h_{2, i} \lambda_{i}^{2}}{2}+\frac{h_{1, i} \lambda_{i}^{2}}{2}\left[\frac{1}{\lambda_{i}}-\frac{E\left[x_{i}\right]^{2}}{P_{2, i}}-\frac{1}{P_{1, i}}\right]\right\} \\
\frac{d^{2} E[T C U(T)]}{d T^{2}}=\frac{2 K_{\pi 0}}{T^{3}}+\frac{2 K_{0}}{T^{3}}+\sum_{i=1}^{L}\left\{\frac{2 K_{i}}{T^{3}}\right\}>0
\end{aligned}
\end{aligned}
$$

Since $K_{\pi 0}, K_{0}, T$, and $K_{i}$ in Eq. (26) are positive; therefore, $E[T C U(T)]$ is convex. It follows by setting Eq. (25) equal to zero; the optimal $T^{*}$ is derived as follows:

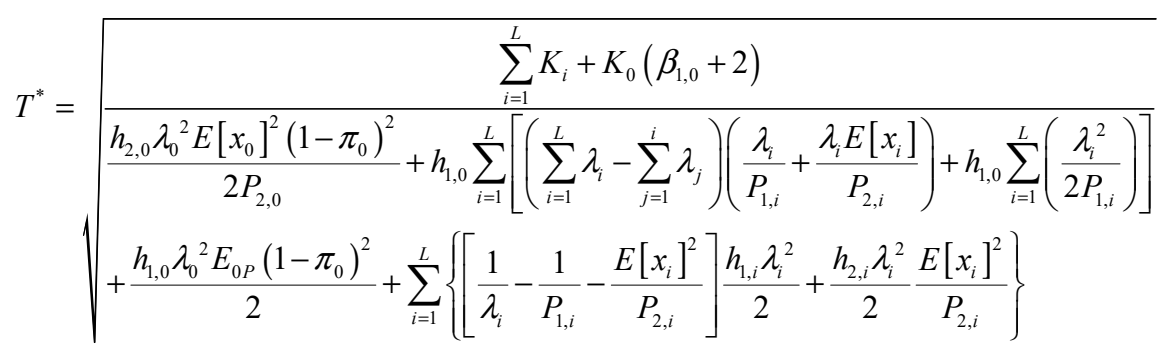

\section{Numerical example}


This section uses a numerical illustration to demonstrate how our multiproduct postponement model works. The assumed values for variables in stages one and two are listed in Tables 1 and 2. In contrast, the assumption of system variables' values for the single-stage model of the same problem (with five end products) is listed Table B-1 (refer to Appendix B).

Table 1

The assumption of stage one's system variables in our illustration

\begin{tabular}{cccccccc}
\hline$\lambda_{0}$ & $K_{0}$ & $\pi_{0}$ & $C_{\mathrm{R}, 0}$ & $h_{1,0}$ & $\mathrm{i}_{0}$ & $h_{2,0}$ & $\beta_{2,0}$ \\
17406 & $\$ 8500$ & 0.4 & $\$ 25$ & $\$ 8$ & 0.2 & $\$ 8$ & 0.4 \\
\hline$C_{0}$ & $\gamma$ & $x_{0}$ & $P_{2,0}$ & $P_{1,0}$ & $\delta$ & $\beta_{1,0}$ \\
\end{tabular}

Table 2

The assumption of system variables' values in stage two of our illustration

\begin{tabular}{ccccccccccc}
\hline Item $i$ & $C_{i}$ & $P_{1, i}$ & $\lambda_{i}$ & $K_{i}$ & $x_{i}$ & $P_{2, i}$ & $i_{i}$ & $h_{2, i}$ & $C_{\mathrm{R}, i}$ & $h_{1, i}$ \\
\hline 1 & $\$ 40$ & 112258 & 3000 & $\$ 8500$ & $2.5 \%$ & 89806 & 0.2 & $\$ 16$ & $\$ 25$ & $\$ 16$ \\
2 & $\$ 50$ & 116066 & 3200 & $\$ 9000$ & $7.5 \%$ & 92852 & 0.2 & $\$ 18$ & $\$ 30$ & $\$ 18$ \\
3 & $\$ 60$ & 120000 & 3400 & $\$ 9500$ & $12.5 \%$ & 96000 & 0.2 & $\$ 20$ & $\$ 35$ & $\$ 20$ \\
4 & $\$ 70$ & 124068 & 3600 & $\$ 10000$ & $17.5 \%$ & 99254 & 0.2 & $\$ 22$ & $\$ 40$ & $\$ 22$ \\
5 & $\$ 80$ & 128276 & 3800 & $\$ 10500$ & $22.5 \%$ & 102621 & 0.2 & $\$ 24$ & $\$ 45$ & $\$ 24$ \\
\hline
\end{tabular}

To obtain the optimal operating $T^{*}$ and $E\left[T C U\left(T^{*}\right)\right]$ for our multiproduct postponement model featuring rework, commonality, and external provide works, one can apply the resulting formulas (27) and (24), and find that $T^{*}=0.5689$ and $E\left[T C U\left(T^{*}\right)\right]=\$ 2,081,646$. The influence of variations in the outsourcing portion $\pi_{0}$ on diverse system-relevant parameters has been further investigated and displayed in Table C-1 (see Appendix C). Consequently, numerous in-depth system characteristics are revealed as follows.

\subsection{Convexity of $E[T C U(T)]$}

Fig. 4 depicts $E[T C U(T)]$ 's behavior concerning $T$. As the cycle time departs from $T^{*}, E[T C U(T)]$ knowingly increases.

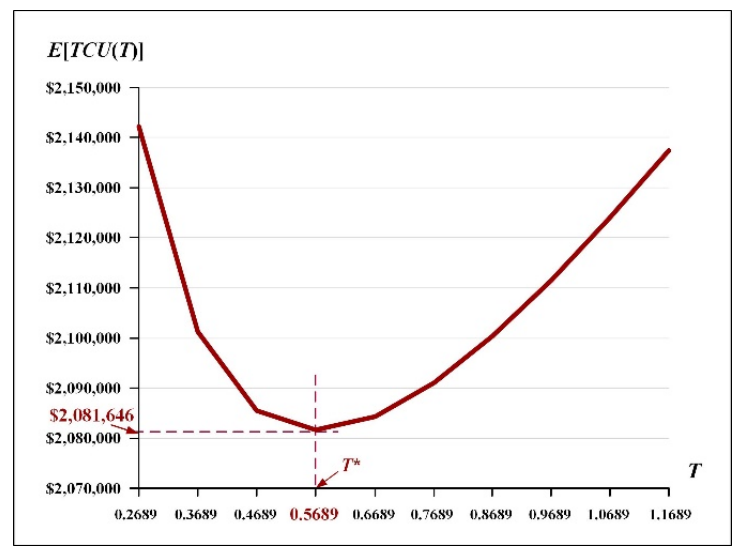

Fig. 4. Behavior of $E[T C U(T)]$ concerning $T$

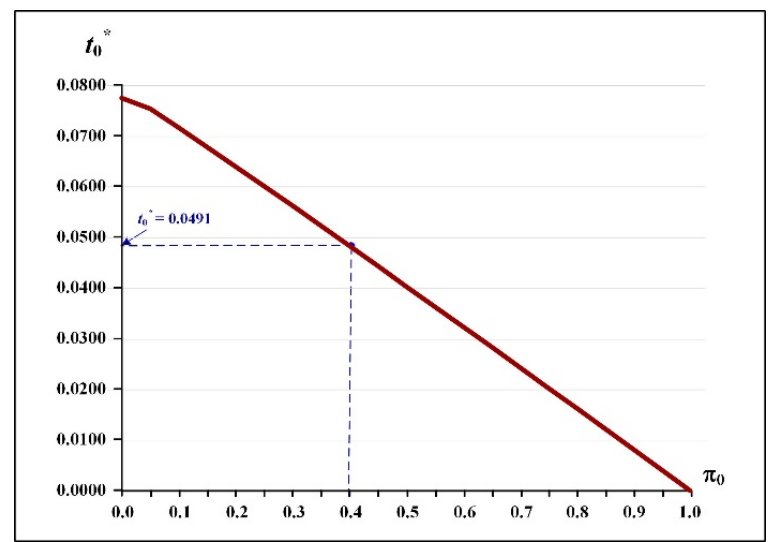

Fig. 5.The impact of variations in common parts' outsourcing portion $\pi_{0}$ on $t_{0}^{*}$ in stage 1

\subsection{Influence of outsourcing percentage on in-house fabrication time/utilization}

Since this research considers an outsourcing strategy on the common parts with $\pi_{0}=0.4$, the summation of stage one's manufacturing uptime and rework time $t_{0} *$ declines to 0.0491 from 0.0787 (year), that is a drop of $37.61 \%$. Fig. 5 also shows that as $\pi_{0}$ increases, $t_{0} *$ knowingly decreases. Fig. 6 exhibits the analytical outcome of the total utilization (in percentage) of the system vis-à-vis $\pi_{0}$. It specifies that in this example (i.e., $\pi_{0}=0.4$ and $\gamma=0.5$ ), utilization decreases to $23.89 \%$ from $29.64 \%$, that is a drop of $19.40 \%$. Figure 6 also indicates that as $\pi_{0}$ increases, utilization decreases knowingly.

Fig. 7 compares our study's utilization with other similar models. Since our research considers an outsourcing strategy in stage one, our utilization declines to $23.89 \%$ (from $29.64 \%$ ), or a $19.40 \%$ lower than that in a similar two-stage model without outsourcing plan (see Fig. 7). Further, it shows a $22.99 \%$ less in utilization (i.e., declining from $31.02 \%$ to $23.89 \%$; see Fig. 7) compared to that in a one-stage same fabrication model with neither postponement nor outsourcing. 


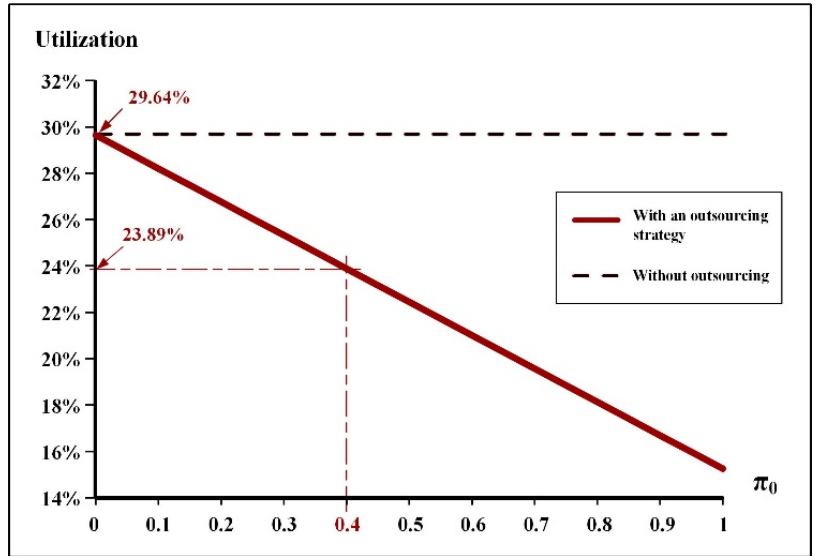

Fig. 6. The behavior of utilization (in \%) vis-à-vis $\pi_{0}$

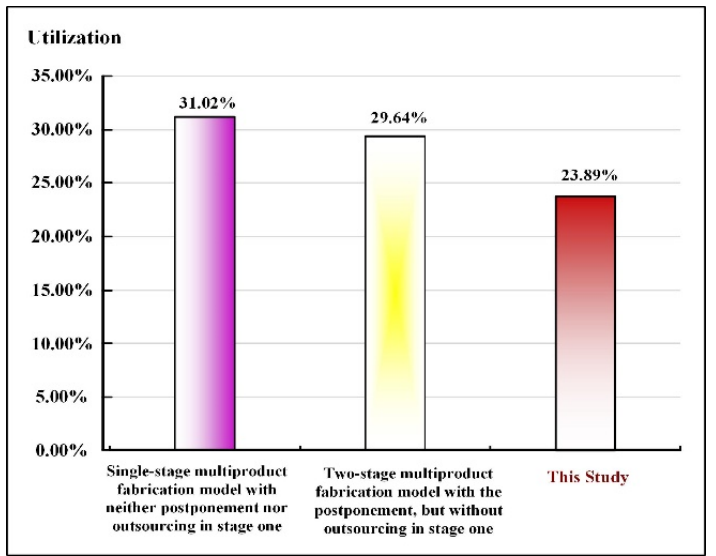

Fig. 7. Comparing our study's utilization with that in similar models

\subsection{Impact on the system relevant cost}

Fig. 8 compares this study's $E\left[T C U\left(T^{*}\right)\right]$ with other similar models. An outsourcing strategy helps this study to reduce $19.40 \%$ in utilization compared to that in the same two-stage model without outsourcing at a $5.46 \%$ increase in $E\left[T C U\left(T^{*}\right)\right]$ (i.e., increasing from $\$ 1,973,946$ to $\$ 2,081,646$; see Fig. 8). Further, we pay a $1.74 \%$ cost increase (i.e., increasing from $\$ 2,046,098$ to $\$ 2,081,646$ ) for a decrease of $22.99 \%$ in utilization compared to that in a one-stage same fabrication model with neither postponement nor outsourcing.

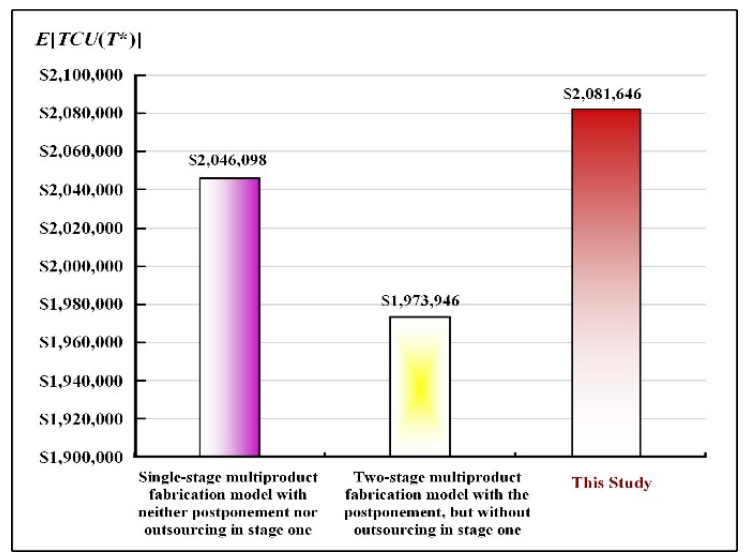

Fig. 8. Comparing our study's $E\left[T C U\left(T^{*}\right)\right]$ with other similar models

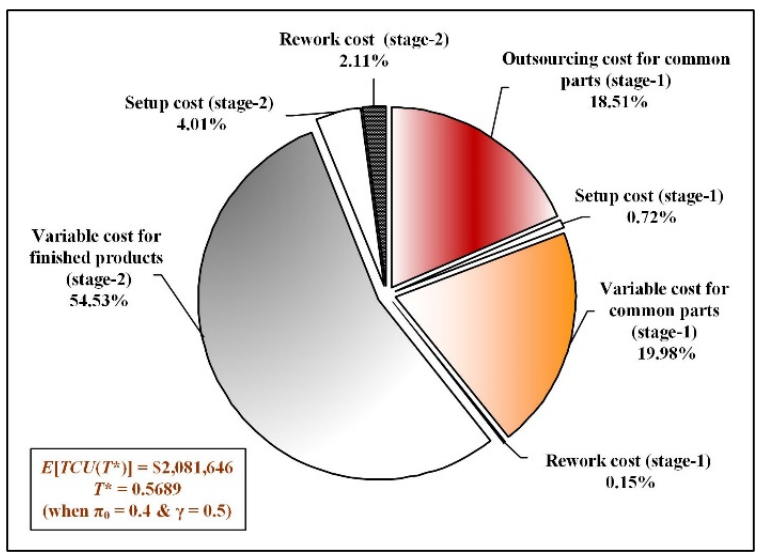

Fig. 9. The breakup of $\left[T C U\left(T^{*}\right)\right]$

Moreover, the breakup of the system cost is analyzed and exhibited in Fig. 9. It specifies that for $\pi_{0}=0.4$ and $\gamma=0.5$, the main contributors to $E\left[T C U\left(T^{*}\right)\right]$ add up $93.02 \%$. They are the variable costs for finished products $(54.53 \%)$ and common parts $(19.98 \%)$, and mutual parts' outsourcing cost $(18.51 \%)$. The rework cost is $2.26 \%$ of the system cost. Fig. 10 reveals the impact of average rework cost's ratio against unit cost on $\left[T C U\left(T^{*}\right)\right]$. It confirms that the ratio average rework cost at 0.6 , our optimal $\left[T C U\left(T^{*}\right)\right]$ is $\$ 2,081,646$. As the average rework cost ratio rises, $\left[T C U\left(T^{*}\right)\right]$ increases accordingly.
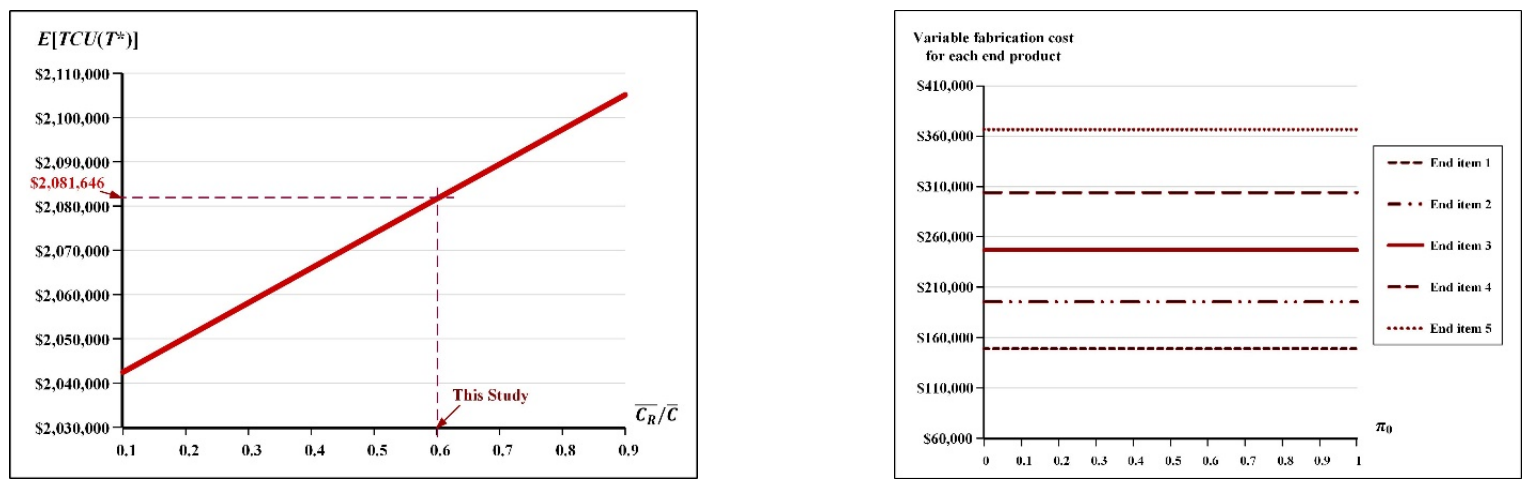
Fig. 10. The behavior of $\left[T C U\left(T^{*}\right)\right]$ regarding average rework cost's ratio against the unit cost

Fig. 11 depicts the variable fabrication costs for each end product concerning $\pi_{0}$. It explicitly depicts our model can analyze the detailed performance of stage two of the proposed system. However, it reveals that each finished goods' variable cost is different, and the changes in $\pi_{0}$ have no effects on these separated variable costs. The collective effect of the mutual part's completion rate $\gamma$ and add-up percentage of outsourcing unit cost $\beta_{2,0}$ on $E\left[T C U\left(T^{*}\right)\right]$ is studied and revealed in Fig. 12. As $\beta_{2,0}$ increases, $E\left[T C U\left(T^{*}\right)\right]$ upsurges enormously, especially when $\gamma$ is higher. If the add-up percentage of outsourcing unit $\operatorname{cost} \beta_{2,0}$ is high, then as $\gamma$ rises, $E\left[T C U\left(T^{*}\right)\right]$ increases significantly.

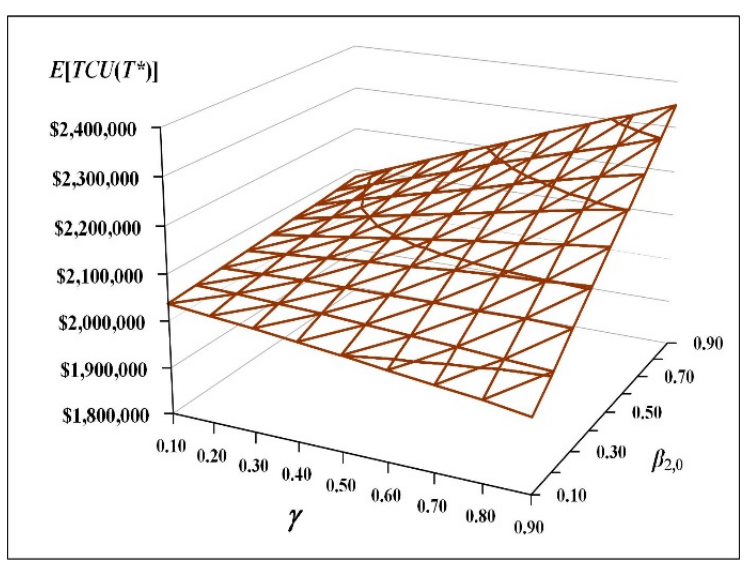

Fig. 12. The collective influence of $\gamma$ and $\beta_{2,0}$ on $E\left[T C U\left(T^{*}\right)\right]$

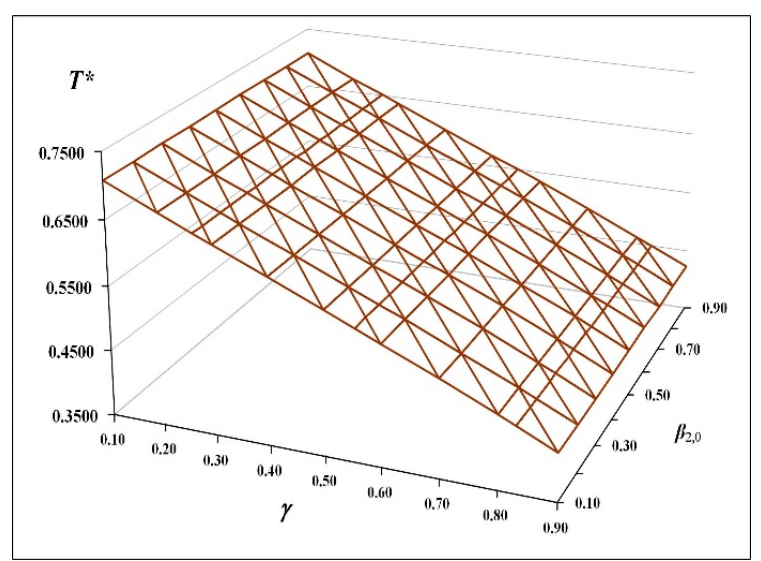

Fig. 13. The collective effect of $\beta_{2,0}$ and $\gamma$ on $T^{*}$

\subsection{Collective influence on $T^{*}$ and the relationship between $\delta$ and $\gamma$ on $E\left[T C U\left(T^{*}\right)\right]$}

Fig. 13 exhibits the collective effect of the add-up percentage of outsourcing unit cost $\beta_{2,0}$ and the completion rate of common part $\gamma$ on $T^{*}$. As $\gamma$ rises, $T^{*}$ declines significantly, and $T^{*}$ changes trivially as $\beta_{2,0}$ increases. Fig. 14 reveals the influence of the nonlinear (e.g., $\delta=\gamma^{3}$ ) and linear (i.e., $\delta=\gamma$ ) relationships on $E\left[T C U\left(T^{*}\right)\right]$. It shows our model can disclose the diverse relationships between the mutual part's $\delta$ values and its relating $\gamma$ values on $E\left[T C U\left(T^{*}\right)\right]$. It also indicates that for $\gamma=0.5$, the distinct values of $E\left[T C U\left(T^{*}\right)\right]$ for both relationships of linear $\left(\delta=\gamma^{1}\right)$ and nonlinear $\left(\delta=\gamma^{3}\right)$.

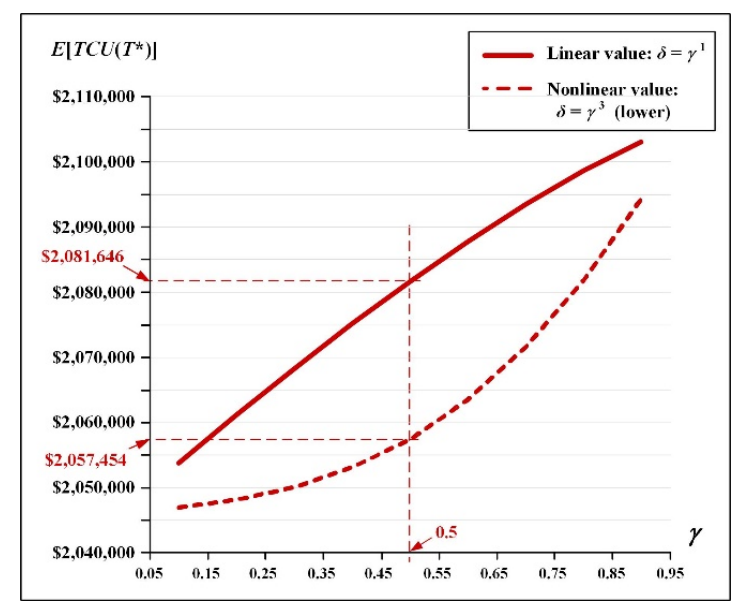

Fig. 14. The impact of linear and nonlinear relationships on $E\left[T C U\left(T^{*}\right)\right]$

\section{Conclusions}

To satisfy customer demands that simultaneously emphasize quality, variety, and fast response time, most present-day manufacturers plan their multi-product fabrication by incorporating a postponement strategy, rework process, and an outsourcing option. Motivated by the viewpoints above, this study builds a two-stage delayed differentiation model to offer a decision support system to address customers' external expectations while optimizing internal operating expenses and machine utilization. Modeling, analysis, and optimization processes help us derive an optimal cost-minimization rotation cycle (refer to Section 2 to Subsection 3-2). A numerical example demonstrates our result's applicability. It enables the 
exploration of collective and individual influences of reworking, postponement, and outsourcing to external providers on the studied problem (see Numerical example section and Tables C-1 for details). The examples comprise

(1) The optimal replenishing cycle and convexity of the cost function (refer to Fig. 4);

(2) Influence of changes in outsourcing percentage on in-house fabrication time/utilization (refer to Figs. 5-7);

(3) Impact on the system relevant cost (see Figs. 8-12); and

(4) Collective influence on $T^{*}$ and the relationship between $\delta$ and $\gamma$ on $E\left[T C U\left(T^{*}\right)\right]$ (Figs. 13-14).

In summary, our model provides an optimization solution for production and operations planning in various modern industries (e.g., clothing, automotive, household goods, etc.) For future research, combining an end-product multishipment discipline in the same context of the studied problem is worth exploring.

\section{Acknowledgement}

This research is sponsored by the Ministry of Science and Technology of Taiwan (Project\#: MOST 107-2410-H-324-002 \& MOST 110-2221-E-324-013).

\section{Appendix A}

\section{Definition of notation in the mutual parts' making stage}

$\pi_{0} \quad=$ outsourcing portion,

$Q_{0} \quad=$ in-house lot size,

$\lambda_{0} \quad=$ annual demand,

$t_{0}{ }^{*} \quad=$ the optimal uptime,

$h_{1,0}=$ unit holding cost,

$C_{0} \quad=$ unit cost (in-house),

$K_{0} \quad=$ setup cost (in-house),

$K_{\pi 0} \quad=$ fixed outsourcing cost,

$\beta_{1,0}=$ the connecting factor between $K_{\pi 0}$ and $K_{0}$,

$C_{\pi 0}=$ unit outsourcing cost,

$\beta_{2,0}=$ the connecting factor between $C_{\pi 0}$ and $C_{0}$,

$t_{1,0}=$ manufacturing uptime with outsourcing option,

$t_{2,0}=$ nonconforming items' rework time,

$t_{3,0}=$ depleting time,

$P_{1,0} \quad=$ annual manufacturing rate (in-house),

$x_{0}=$ nonconforming percentage,

$d_{1,0}=$ nonconforming mutual parts' fabricating rate (where $d_{1,0}=x_{0} P_{1,0}$ ),

$P_{2,0}=$ annual reworking rate,

$C_{\mathrm{R}, 0}=$ unit rework cost,

$H_{1,0}=$ stock level when uptime ends,

$h_{2,0}=$ unit holding cost for reworked items,

$H_{2,0} \quad=$ stock level when rework ends,

$i_{0}=$ holding cost's relating ratio (where $\left.h_{1, i}=\left(i_{0}\right) C_{i}\right)$,

$H_{3,0} \quad=$ stock level upon receiving outsourced items,

Definition of notation in the end-product making stage (where $i=1,2, \ldots, L$ )

$T=$ the decision variable - rotation cycle length,

$L=$ the number of distinct end products,

$P_{1, i}=$ annual manufacturing rate,

$\lambda_{i} \quad=$ annual demand rate,

$Q_{i} \quad=$ lot size,

$t_{1, i}=$ uptime,

$x_{i}=$ random nonconforming percentage,

$d_{1, i}=$ nonconforming items' manufacturing rate (where $\left.d_{1, i}=x_{i} P_{1, i}\right)$,

$C_{i}=$ unit cost,

$K_{i} \quad=$ setup cost,

$h_{1, i}=$ holding cost,

$t_{i}^{*} \quad=$ the sum of the optimal uptimes,

$h_{2, i}=$ holding cost,

$t_{2, i}=$ rework time, 
$t_{3, i}=$ the depleting time,

$P_{2, i} \quad=$ annual reworking rate,

$H_{1, i} \quad=$ stock level when uptime ends,

$C_{\mathrm{R}, i}=$ unit rework cost,

$H_{2, i} \quad=$ stock level when rework ends,

$H_{i} \quad=$ common parts' stock level when uptime of product $i$ ends,

$I(t)_{i} \quad=$ stock level at time $t$,

$E[T]=$ the expected common cycle time,

$T C(T)=$ system cost in a cycle,

$E[T C(T)]=$ the expected system cost in a cycle,

$E[T C U(T)]=$ the expected system cost per unit time.

\section{Appendix - B}

Table B-1. The assumed values for parameters in a single-stage model of the same problem

\begin{tabular}{|c|c|c|c|c|c|c|c|c|c|c|}
\hline Product $i$ & $\overline{C_{i}}$ & $P_{1, i}$ & $x_{i}$ & $\lambda_{i}$ & $C_{\mathrm{R}, i}$ & $\overline{K_{i}}$ & $h_{1, i}$ & $P_{2, i}$ & $h_{2, i}$ & $\bar{i}$ \\
\hline 1 & $\$ 80$ & 58000 & $5 \%$ & 3000 & $\$ 50$ & $\$ 17000$ & $\$ 16$ & 46400 & $\$ 16$ & 0.2 \\
\hline 2 & $\$ 90$ & 59000 & $10 \%$ & 3200 & $\$ 55$ & $\$ 17500$ & $\$ 18$ & 47200 & $\$ 18$ & 0.2 \\
\hline 3 & $\$ 100$ & 60000 & $15 \%$ & 3400 & $\$ 60$ & $\$ 18000$ & $\$ 20$ & 48000 & $\$ 20$ & 0.2 \\
\hline 4 & $\$ 110$ & 61000 & $20 \%$ & 3600 & $\$ 65$ & $\$ 18500$ & $\$ 22$ & 48800 & $\$ 22$ & 0.2 \\
\hline 5 & $\$ 120$ & 62000 & $25 \%$ & 3800 & $\$ 70$ & $\$ 19000$ & $\$ 24$ & 49600 & $\$ 24$ & 0.2 \\
\hline
\end{tabular}

\section{Appendix - C}

\section{Table C-1}

Influence of variations ins in $\pi_{0}$ on utilization \& various system relevant parameters

\begin{tabular}{|c|c|c|c|c|c|c|c|c|c|c|}
\hline$\pi_{0}$ & $\begin{array}{l}t_{0}^{*} \\
(\mathrm{~A})\end{array}$ & $\begin{array}{c}\% \\
\text { decline in } \\
\text { (A) }\end{array}$ & $\begin{array}{c}\text { Total } \\
\text { uptime } \\
\text { (B) }\end{array}$ & $\begin{array}{c}\% \% \\
\text { decline } \\
\text { in }(\mathrm{B})\end{array}$ & $\begin{array}{l}\text { Utilization } \\
\text { (C) }\end{array}$ & $\begin{array}{c}\% \\
\text { decline } \\
\text { in }(\mathrm{C})\end{array}$ & $\begin{array}{l}\text { Total rework } \\
\text { time (D) }\end{array}$ & $T^{*}$ & $\begin{array}{c}\mathrm{E}\left[T C U\left(T^{*}\right)\right] \\
(\mathrm{E})\end{array}$ & $\begin{array}{c}\% \\
\text { increase } \\
\text { In }(\mathrm{E})\end{array}$ \\
\hline 0.00 & 0.0787 & - & 0.1547 & - & $29.64 \%$ & - & 0.0074 & 0.5468 & $\$ 1,973,946$ & - \\
\hline 0.05 & 0.0766 & $-2.61 \%$ & 0.1546 & $-0.05 \%$ & $28.92 \%$ & $-2.43 \%$ & 0.0075 & 0.5606 & $\$ 1,991,349$ & $0.88 \%$ \\
\hline 0.10 & 0.0728 & $-7.51 \%$ & 0.1510 & $-2.38 \%$ & $28.20 \%$ & $-4.85 \%$ & 0.0074 & 0.5620 & $\$ 2,004,168$ & $1.53 \%$ \\
\hline 0.15 & 0.0689 & $-12.44 \%$ & 0.1474 & $-4.72 \%$ & $27.48 \%$ & $-7.28 \%$ & 0.0074 & 0.5633 & $\$ 2,017,013$ & $2.18 \%$ \\
\hline 0.20 & 0.0650 & $-17.41 \%$ & 0.1437 & $-7.10 \%$ & $26.76 \%$ & $-9.71 \%$ & 0.0074 & 0.5645 & $\$ 2,029,885$ & $2.83 \%$ \\
\hline 0.25 & 0.0610 & $-22.41 \%$ & 0.1400 & $-9.49 \%$ & $26.04 \%$ & $-12.14 \%$ & 0.0073 & 0.5657 & $\$ 2,042,784$ & $3.49 \%$ \\
\hline 0.30 & 0.0571 & $-27.44 \%$ & 0.1363 & $-11.91 \%$ & $25.32 \%$ & $-14.56 \%$ & 0.0073 & 0.5669 & $\$ 2,055,711$ & $4.14 \%$ \\
\hline 0.35 & 0.0531 & $-32.49 \%$ & 0.1325 & $-14.35 \%$ & $24.61 \%$ & $-16.99 \%$ & 0.0072 & 0.5679 & $\$ 2,068,665$ & $4.80 \%$ \\
\hline 0.40 & 0.0491 & $-37.61 \%$ & 0.1287 & $-16.80 \%$ & $23.89 \%$ & $-19.40 \%$ & 0.0072 & 0.5689 & $\$ 2,081,646$ & $5.46 \%$ \\
\hline 0.45 & 0.0451 & $-42.69 \%$ & 0.1249 & $-19.28 \%$ & $23.17 \%$ & $-21.84 \%$ & 0.0071 & 0.5698 & $\$ 2,094,656$ & $6.12 \%$ \\
\hline 0.50 & 0.0410 & $-47.83 \%$ & 0.1210 & $-21.78 \%$ & $22.45 \%$ & $-24.27 \%$ & 0.0071 & 0.5706 & $\$ 2,107,693$ & $6.78 \%$ \\
\hline 0.55 & 0.0370 & $-52.98 \%$ & 0.1171 & $-24.29 \%$ & $21.73 \%$ & $-26.70 \%$ & 0.0070 & 0.5713 & $\$ 2,120,757$ & $7.44 \%$ \\
\hline 0.60 & 0.0329 & $-58.16 \%$ & 0.1132 & $-26.82 \%$ & $21.01 \%$ & $-29.12 \%$ & 0.0069 & 0.5720 & $\$ 2,133,850$ & $8.10 \%$ \\
\hline 0.65 & 0.0288 & $-63.35 \%$ & 0.1093 & $-29.36 \%$ & $20.29 \%$ & $-31.55 \%$ & 0.0069 & 0.5726 & $\$ 2,146,972$ & $8.77 \%$ \\
\hline 0.70 & 0.0247 & $-68.56 \%$ & 0.1053 & $-31.92 \%$ & $19.57 \%$ & $-33.98 \%$ & 0.0068 & 0.5731 & $\$ 2,160,121$ & $9.43 \%$ \\
\hline 0.75 & 0.0206 & $-73.78 \%$ & 0.1013 & $-34.50 \%$ & $18.85 \%$ & $-36.41 \%$ & 0.0068 & 0.5736 & $\$ 2,173,299$ & $10.10 \%$ \\
\hline 0.80 & 0.0165 & $-79.01 \%$ & 0.0973 & $-37.08 \%$ & $18.13 \%$ & $-38.83 \%$ & 0.0067 & 0.5739 & $\$ 2,186,505$ & $10.77 \%$ \\
\hline 0.85 & 0.0124 & $-84.25 \%$ & 0.0933 & $-39.68 \%$ & $17.41 \%$ & $-41.26 \%$ & 0.0067 & 0.5742 & $\$ 2,199,739$ & $11.44 \%$ \\
\hline 0.90 & 0.0083 & $-89.50 \%$ & 0.0893 & $-42.29 \%$ & $16.69 \%$ & $-43.69 \%$ & 0.0066 & 0.5744 & $\$ 2,213,003$ & $12.11 \%$ \\
\hline 0.95 & 0.0041 & $-94.75 \%$ & 0.0852 & $-44.91 \%$ & $15.97 \%$ & $-46.11 \%$ & 0.0065 & 0.5745 & $\$ 2,226,294$ & $12.78 \%$ \\
\hline 1.00 & 0.0000 & $-100.00 \%$ & 0.0750 & $-51.49 \%$ & $15.25 \%$ & $-48.54 \%$ & 0.0060 & 0.5312 & $\$ 2,224,241$ & $12.68 \%$ \\
\hline
\end{tabular}

\section{References}

Abboud, N.E. (1996). The markovian two-echelon repairable item provisioning problem. Journal of the Operational Research Society, 47(2), 284-296.

Abukhader, K.M.S., \& Onbaşığlu, D.Ç. (2021). The effects of total quality management practices on employee performance and the effect of training as a moderating variable. Uncertain Supply Chain Management, 9(3), 521-528.

Al-Salamah, M. (2019). Economic production quantity in an imperfect manufacturing process with synchronous and asynchronous flexible rework rates. Operations Research Perspectives, 6, Art. No. 100103, 1-11.

Al Taweel, A.M. (2019). Sustainable reaction/separation engineering: A critical tool for the long-term wellbeing of the world. Journal of King Saud University - Engineering Sciences, 31(2), 105.

Araz, C., Ozfirat, P.M., \& Ozkarahan, I. (2007). An integrated multi-criteria decision-making methodology for outsourcing management. Computers \& Operations Research, 34(12), 3738-3756. 
Arnold, U. (2000). New dimensions of outsourcing: a combination of transaction cost economics and the core competencies concept. European Journal of Purchasing \& Supply Management, 6(1), 23-29.

Chiu, Y.-S.P., Chiu, V., Wang, Y., \& Hwang, M.-H. (2020a). A postponement model for multi-item replenishment decision considering overtime, commonality, and quality reassurance. International Journal of Industrial Engineering Computations, 11(4), 509-524.

Chiu, Y.-S.P., Zhao, Z.-Y., Chiu, S.W., \& Chiu, V. (2020b). A vendor-buyer coordinated system featuring an unreliable machine, scrap, outsourcing, and multiple shipments. International Journal of Industrial Engineering Computations, 11(3), 341-358.

Chiu, S.W., Chiu, T., Chiu, Y-S.P., \& Lin, H-D. (2021). Economic manufacturing quantity model with machine failure, overtime, and rework/disposal of nonconforming items. Management and Production Engineering Review, 12(1), 3-16.

Dan-asabe, B., Yaro, S.A., Yawas, D.S., \& Aku, S.Y. (2019). Statistical modeling and optimization of the flexural strength, water absorption and density of a doum palm-Kankara clay filler hybrid composite. Journal of King Saud University Engineering Sciences, 31(4), 385-394.

Daryanto, Y., \& Christata, B.R. (2021). Optimal order quantity considering carbon emission costs, defective items, and partial backorder. Uncertain Supply Chain Management, 9(2), 307-316.

Duan, J., Li, H., \& Zhang, Q. (2021) Multiobjective optimization of buffer capacity allocation in multiproduct unreliable production lines using improved adaptive NSGA-II algorithm. Kuwait Journal of Science, 48(1), 72-84.

Guericke, S., Koberstein, A., Schwartz, F., \& Voß, S. (2012). A stochastic model for the implementation of postponement strategies in global distribution networks. Decision Support Systems, 53, 294-305.

Homolka, S., Zallet, J., Albert, H., Witt, A-K., \& Kranzer, K. (2019). Introduction of quality management in a National Reference Laboratory in Germany. PLoS ONE, 14 (10), Art. No. e0222925.

İnkaya, T., Armbruster, D., Li, H., \& Kempf, K.G. (2018). Product variety strategies for vertically differentiated products in a two-stage supply chain. International Journal of Production Research, 56(17), 5930-5944.

Iyer, A.V., Deshpande, V., \& Wu, Z. (2003). A postponement model for demand management. Management Science, 49(8), 983-1002.

Jewkes, E.M., \& Alfa, A.S. (2009). A queueing model of delayed product differentiation. European Journal of Operational Research, 199, 734-743.

Kaipia, R., \& Turkulainen, V. (2016). Managing integration in outsourcing relationships - The influence of cost and quality priorities. Industrial Marketing Management, 61, 114-129.

Krishnamoorthi, C., \& Panayappan, S. (2013). An EPQ model for an imperfect production system with rework and shortages. International Journal of Operational Research, 17(1), 104-124.

Li, J. (2004). Performance analysis of production systems with rework loops. IIE Transactions, 36(8), $755-765$.

Sadjadi, S.J., Asadi, H., Sadeghian, R., \& Sahebi, H. (2018). Retailer Stackelberg game in a supply chain with pricing and service decisions and simple price discount contract. PLOS ONE, 13(4), Art. No. e0195109.

Skowronski, K., Benton, W.C. Jr. (2018). The influence of intellectual property rights on poaching in manufacturing outsourcing. Production and Operations Management, 27(3), 531-552.

Siouris, G.-J., Skilogianni, D., Karagrigoriou, A. (2019). Post model correction in risk analysis and management. International Journal of Mathematical, Engineering and Management Sciences, 4(3), 542-566.

Suroso, A.I., Tandra, H., Syaukat, Y., Najib, M. (2021). The issue in Indonesian palm oil stock decision making: Sustainable and risk criteria. Decision Science Letters, 10(3), 241-246. 
(C) 2022 by the authors; licensee Growing Science, Canada. This is an open access article distributed under the terms and conditions of the Creative Commons Attribution (CC-BY) license (http://creativecommons.org/licenses/by/4.0/). 